Jpn. J. Human Genet. 25, 39-45, 1980

\title{
A CASE OF PARTIAL 2p TRISOMY WITH NEUROBLASTOMA
}

\author{
Hitomi Nagano, Yuko Kano, Seiko Kobuchi, and Takashi Kajitani \\ Department of Pediatrics, Kawasaki Hospital, Kawasaki \\ Medical School, Okayama 700, Japan
}

\begin{abstract}
Summary Reported is the first Japanese case of partial $2 p$ trisomy with concomitant neuroblastoma occurring in an 8 month-old boy. The family history disclosed that his father, paternal grandfather and uncle, suffering from congenital cataract and microphthalmos, were carriers of reciprocal translocation between distal segments of the short arm of Chromosomes 2 and $16(\mathrm{p} 13, \mathrm{p} 11)$. The karyotype of the patient revealed an abnormally long short arm in one of the pair of Chromosome 16 that was similar to the change of Chromosome 16 found in his father and the other paternal members of his family, while Chromosome 2 appeared normal. Subsequently the patient was interpreted to be trisomic for many distal segments of $2 p$ and monosomic for almost entire segments of 16p. Clinical features of the present case demonstrated many characteristics common to those of the reported cases of partial $2 p$ trisomy syndrome in foreign countries. Relation of this rare chromosomal abnormality to the concomitant occurrence of neuroblastoma was briefly discussed.
\end{abstract}

\section{INTRODUCTION}

A little more than 10 cases of partial $2 p$ trisomy syndrome seem to have been reported in world literatures (Stoll et al., 1974; Francke, 1976; Cassidy et al., 1977; Armendares and Salamanca-Gómez, 1978), but we are not aware of similar report in Japan. Because of the characteristic clinical manifestations like those reported by Stoll et al. (1974) and Cassidy et al. (1977), the distinct entity of this syndrome appears to have been established. Any malignant neoplasia has not been reported, however, to occur in association with this syndrome.

We report a new case of partial $2 p$ trisomy syndrome associated with neuroblastoma and review the pertient literatures with a brief discussion on the relationship between this chromosomal abnormality and the malignancy.

Received November 4, 1979 


\section{CASE REPORT}

An 8 month-old male infant was admitted to our hospital with mental and growth retardation as the chief complaint. He was born as the term product of uneventful pregnancy, when his mother was 25 years-old, primiparous, and his father was 23 years-old. His birth was also uneventful and he weighed 2,590 g at birth. Although his parents had no consanguinity, his father, paternal grandfather and uncle were found to have congenital cataract and microphthalmos.

When first seen at the age of 8 months, his body status was below the 2 nd standard deviation both for height and weight, showing $65.5 \mathrm{~cm} 6,420 \mathrm{~g}$, respectively. His motor activity appeared to be also underdeveloped, and he was not able to control the head even at that time. The face of the patient appeared very unusual because he had microcephaly, frontal bossing, ocular hypertelorism with ptosis, broad flat pugnose with triangular nostrils and micrognathia (Figs. 1 and 2). He also showed bilateral microphthalmos and congenital cataract. A midsystolic murmur was audible in the cardiac base region. The abdomen was distended with venous dilatation over its wall, the liver was palpable $3.5 \mathrm{f}$.w. below the right costal margin showing hard consistency, and the spleen was also palpable $1.5 \mathrm{f}$.w. below the left costal margin. Multiple bluish subcutaneous nodules measuring up to $0.6 \mathrm{~cm}$ in diameter were present in the left armpit, left anterior chest wall and right groin. His penis was extremely small and appeared as if it had been almost entirely embedded in the scrotum.

He was diagnosed neuroblastoma by histological study from the biopsy of an axillary subcutaneous nodule.

And, he had multiple foci of metastasis within the liver, lung, skin, and bone marrow. The patient received irradiation and chemotherapy and he has survived now ( 2 years 5 months old).

\section{CYTOGENETIC STUDIES}

Chromosome study was made on the patient, the parents and some of his relatives by the use of cultured peripheral blood lymphocytes, and Giemsa-banding technique was applied for detailed analysis. The karyotype of the patient consisted of $46, \mathrm{XY}$, in which the short arm in one of the pair of Chromosome 16 was found to be abnormally long, suggesting additional segments derived somewhere else (Fig. 3). Among his individual chromosomes other than Chromosome 16, however, any kind of translocation was not identifiable, which should have been responsible for this anomaly in Chromosome 16.

His healthy mother indicated normal karyotype, but his father, suffering from congenital cataract and microphthalmos, was demonstrated to have abnormal karyotype, in which reciprocal translocation was evident in between many distal 


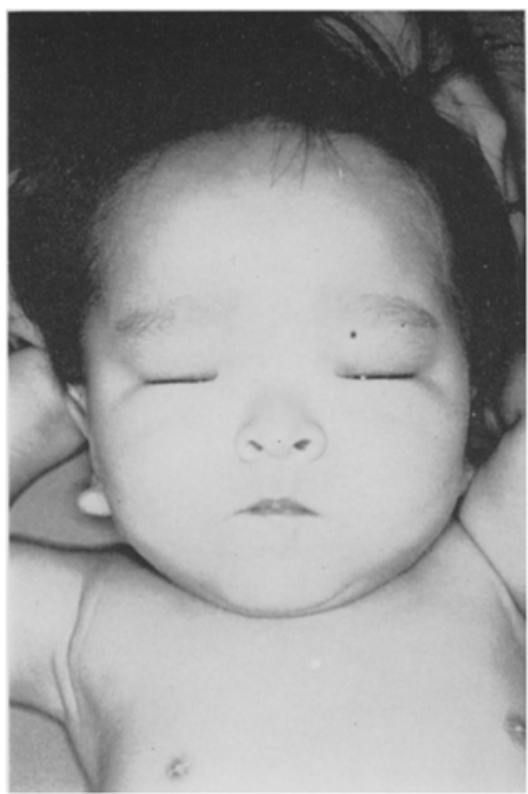

Fig. 1. Appearance of the patient's face showing characteristic changes in the nose and eyes.

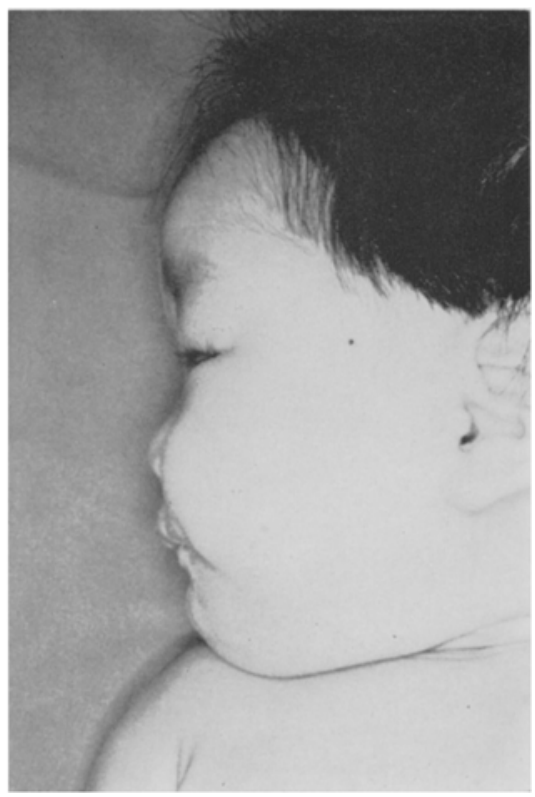

Fig. 2. The profile of the patient indicating frontal bossing.

segments of the short arm in one of the pair of Chromosome 2 and almost entire segments of the short arm in one of the pair of Chromosome $16(46, \mathrm{XY}, \mathrm{t}(2,16)$ (p13, p11)) (Fig. 4). Moreover, his paternal grandfather and uncle, who also had similar cataract and microphthalmos, were also found to have chromosomal abnormality exactly identical to that of his father (Fig. 5).

Based on these chromosomal abnormalities found in his father and the others, it may be reasonablly assumed that the anomaly of the short arm in Chromosome 16 in the present case would have been originated form similar change of Chromosome 16 secondary to the translocation from Chromosome 2 in the paternal members of his family. Therefore, it may be readily interpreted that the patient has partial trisomy of the short arm in Chromosome 2 for the segments from p13 to pter and partial monosomy of the short arm of Chromosome 16 for the segments from p11 to pter.

\section{DISCUSSION}

Partial $2 p$ trisomy syndrome is reported to be characterized by combinations of severe mental and growth retardation and many abnormalities of the face, eyes, external genitalia and others (Stoll et al., 1974; Francke, 1976; Cassidy et al., 1977; Armendares and Salamanca-Gómez, 1978) (Fig. 6). The clinical feature of the 


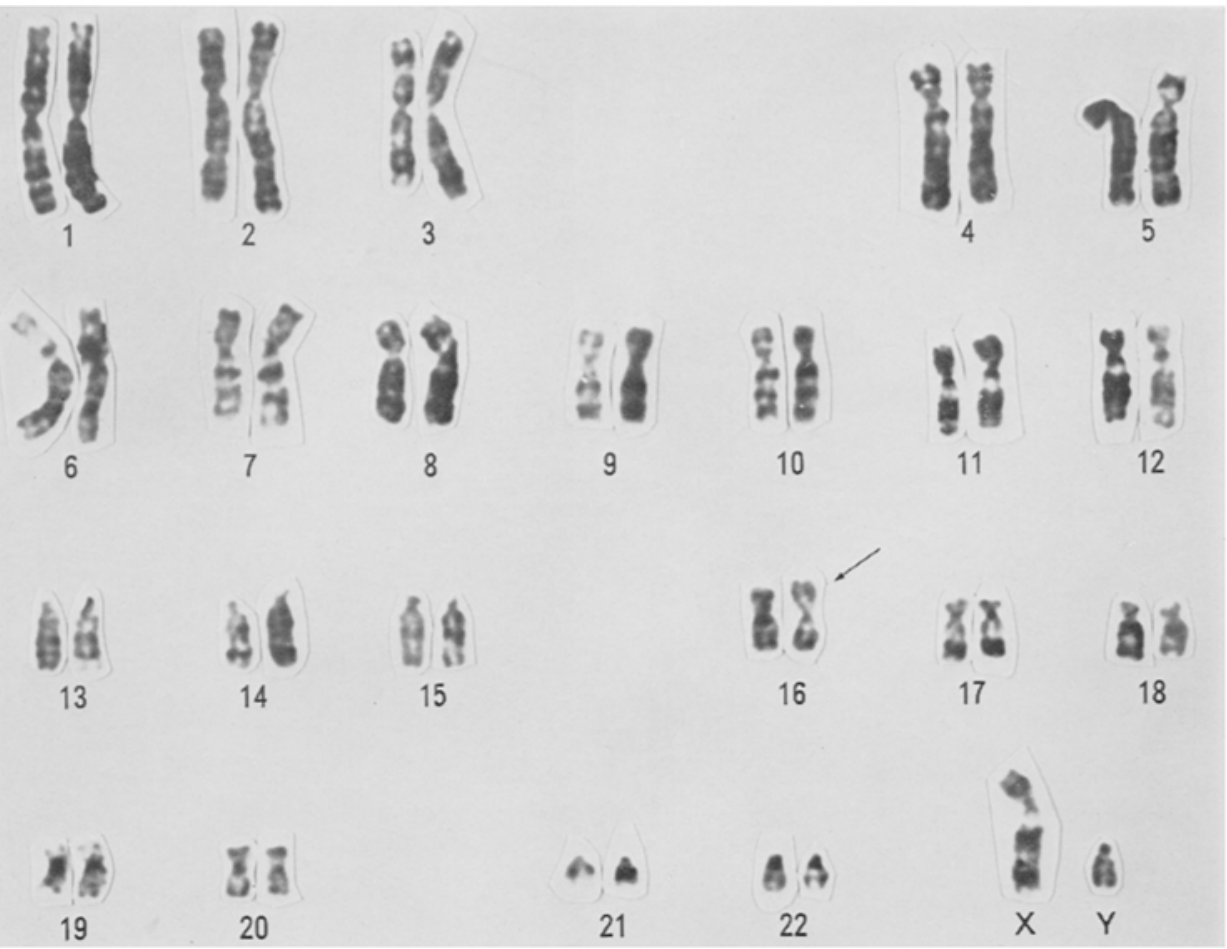

Fig. 3. The G-banded karyotype of the patient showing an abnormally long short arm in Chromosome 16 (arrow).
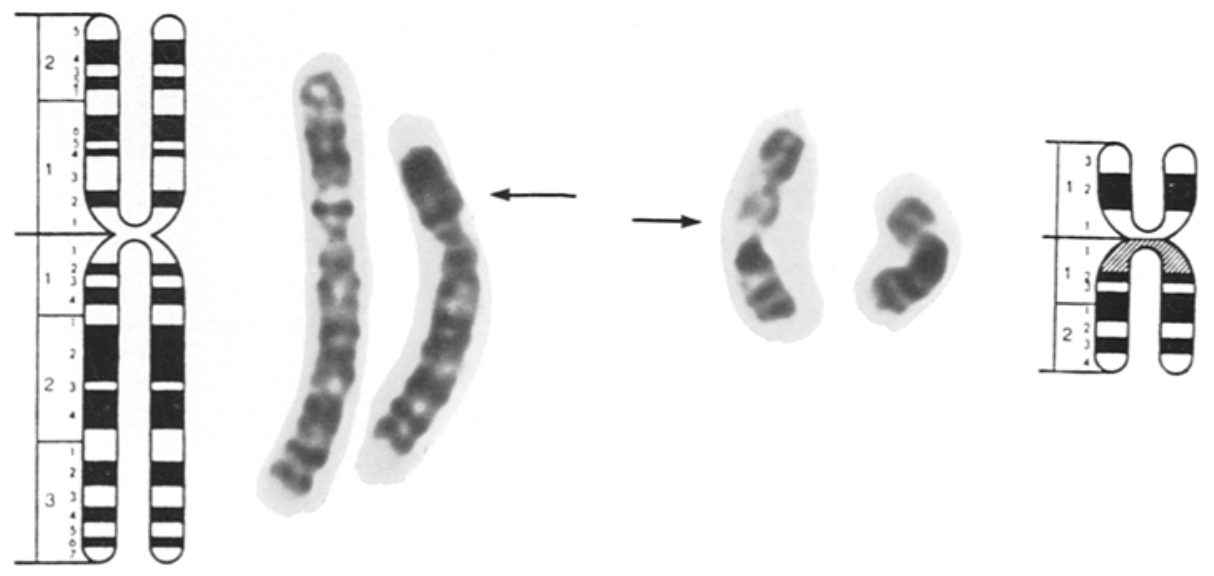

Fig. 4. Close-up and illustration of the father's reciprocal translocation. 


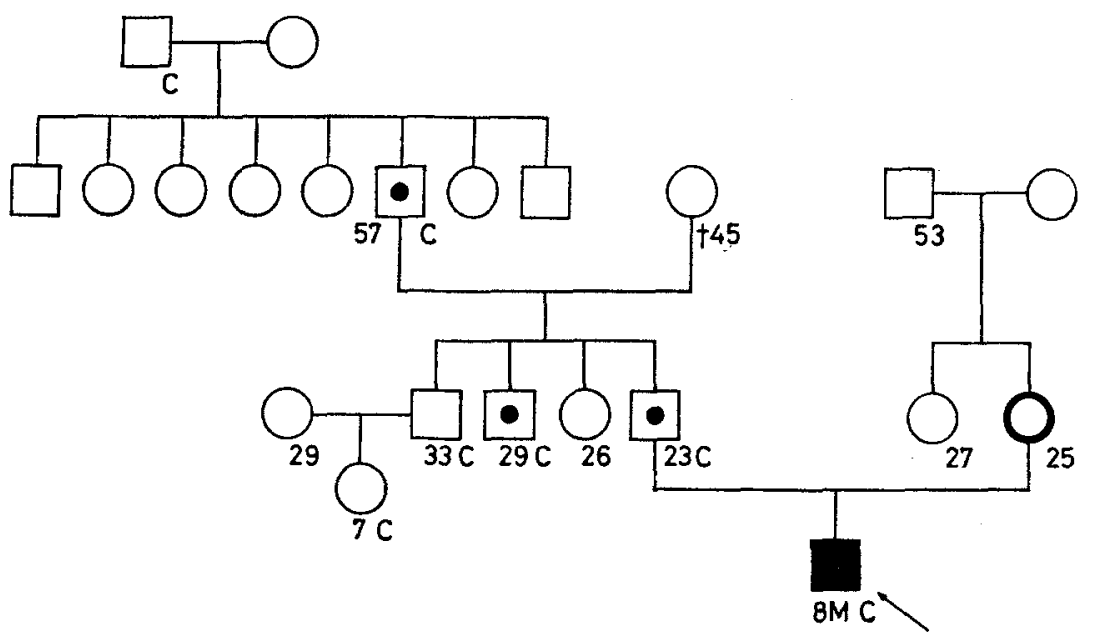

\section{O NORMAL KARY OTYPE $\square+2 p 13$ \\ $[\mathrm{t}(2.16)$ (p13pll) c: CATARACTA}

Fig. 5. The family tree of the patient showing the paternal trait of inheritance.

FEATURES OF THE DISTAL 2P TRISOMY SYNDROME

GENERAL

SEVERE MENTAL RETARDATION GROWTH DEFICIENCY

DEVELOPMENTAL DEFICIENCY

DELAYED BONE AGE

FACIAR

MICRO-OT MICREN-CEPHALY

FRONTAL BOSSING

HY PERTELORISM

EPICANTHAL FOLOS

PTOSIS

STRABISMUS

SEVERE MYOPIA

IACRYMAL DUCT STENOSIS

BROAD FLAT NASAL BRIDCE

PUE NOSE

WIOE PHILTRUM

NARROW HIGH PALATE

BROAD GUMS

MICROENAIHIA

ABNORMAL EAR SHAPE

$$
\text { SKEIETAL }
$$

ABNORMAL STERNAL SEGMENTATION PECTUS EXCAVATUM

SCOLIOSIS AND/OR KYPHOSIS

SPLAYED DISTAL PHALANGES

CAP BETWEEN TOES I AND?

VISCERAL

HEART DEFECT Or MURMUR

SMALL EURIED PENIS *

CRYPTORCHIDISM *

ITPOTONIA

SEIZURES

\begin{tabular}{|c|c|c|c|c|c|c|c|c|c|c|}
\hline \multicolumn{11}{|c|}{ NUMBER OF CASES } \\
\hline 1 & 2 & 3 & 4 & 5 & 6 & 7 & 8 & 9 & 10 & $\mathrm{Pt}$ \\
\hline & & & & & & & & 8 & 6 & . \\
\hline 4 & & & & & 8 & 8 & 83 & & & \\
\hline
\end{tabular}
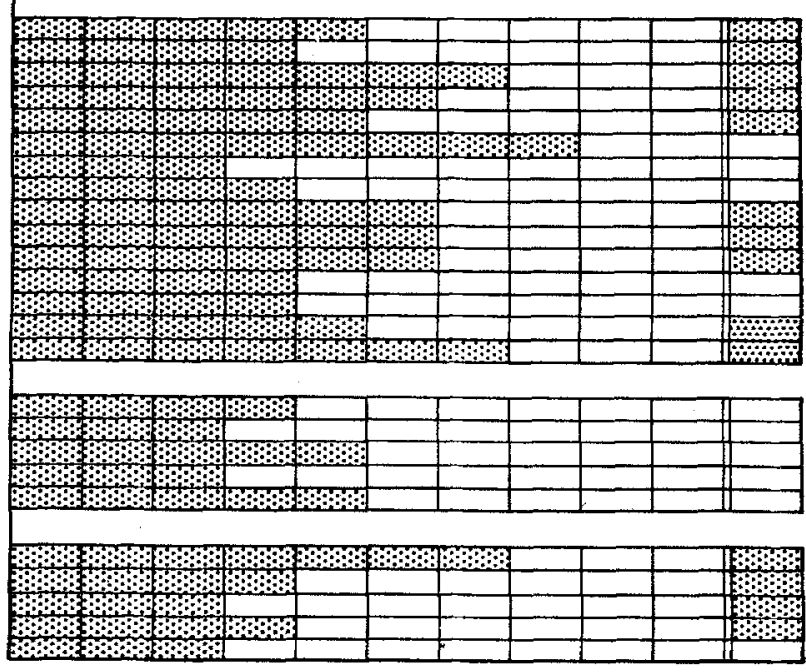

$\square$ POSITIVE $\square$ NEGATIVE

Fig. 6. Clinical manifestations of the present case in comparison with those of the reported cases reviewed by Cassidy et al. (PT with arrow). 
present case appeared to be consistent with many of these characteristics (Fig. 6). The abnormal karyotype of the present case was interpreted to have resulted from a paternal adjacent -1 meiotic segregation and his chromosomal imbalance appeared to be attributable to trisomy for the segments $2 \mathrm{p} 13 \rightarrow$ pter and monosomy for the segments $16 \mathrm{p} 11 \rightarrow$ pter. In the previously reported cases, however, the trisomy for $2 \mathrm{p}$ consisted of smaller numbers of segments distal to $\mathrm{p} 23$ or $\mathrm{p} 21$, as compared to that in the present case. Although the degree of phenotypical disturbances in this syndrome could be assumed to be correlated to numbers of segments in the trisomy, it does not seem to have been established exactly how segments in the trisomy are correlated to the manifestation of the clinical features. The clinical manifestation of the present case is listed in Table 1 for comparison with that of the reported cases reviewed by Cassidy et al. (1977).

In addition to the chromosomal anomaly was found multiple metastatic neuroblastoma in the present case and its primary focus was supposed to be in the paravertebral sympathetic chain in the abdomen because of the presence of the unusual calcification around the spine. The concurrence of $2 p$ partial trisomy and nueroblastoma in the present case may be more than an incidental occurrence because of the rarity of both diseases. However, no malignancy has been reported to occur in association with $2 \mathrm{p}$ partial trisomy syndrome. It is well known that varieties of chromosomal abnormalities may be present in some cases of retinoblastoma, Wilms' tumor (Giangiacomo et al., 1974) and many others apart from $\mathrm{ph}^{1}$ chromosome in adult chronic myeloid leukemia (Allderdice et al., 1969; Wilson et al., 1969; Ozawa, 1974; Gieser, 1969). It seems probable that deletion of the long arm in Group D chromosomes can sometimes be related to the occurrence of retinoblastoma, and recently a Japanese case of neuroblastoma was reported by Yamazaki to be associated with 8p-monosomy (3q-trisomy) (Yamazaki, 1978). From these previous observations on the relationship between the chromosomal abnormalities and malignancies, it seems more likely for the present case that its $16 \mathrm{p}$-monosomy rather than its $2 \mathrm{p}$-trisomy could be related to the occurrence of neuroblastoma. Further study should be instituded, however, for the establishment of the relationship between this rare chromosomal anomaly and neuroblastoma.

It may be of interest that the present case appears to show better prognosis as compared with ordinary cases of neuroblastoma without chromosomal anomaly and he is doing well at the present time 12 months after the admission.

Acknowledgements We very appreciate Dr. J. Furuyama and Dr. N. Suehara, Department of Human Genetics, Hyogo Medical College, for his helpful advice to the chromosome study and Ms. C. Korenobu in our hospital for her technical assistance.

\section{REFERENCES}

Allderdice, P.W., Davis, J.G., and Miller, O.J. 1969. The 13q-deletion syndrome. Am. J. Hum. Genet. 21 : $499-512$. 
Armendares, S., and Salamanca-Gómez, F. 1978. Partial 2p trisomy (p21Mpter) in two siblings of a family with a $2 p-: 15 q+$ translocation. Clinic. Genet. 13: 17-24.

Cassidy, S.B., Heller, R.M., Chazen, E.M., and Engel, E. 1977. The chromosome 2 distal short arm trisomy syndrome. J. Pediat. 91: 934-938.

Francke, U., and Jones, K.L. 1976. The 2p partial trisomy syndrome. Am. J. Dis. Child. 130: $1244-1249$.

Giangiacomo, J., Penchansky, L., Monteleone, P.L., and Thompson, J. 1974. Bilateral neonatal Wilm's tumor with B-C chromosomal translocation. J. Pediatr. 85: 98-100.

Gieser, C.F., and Schindler, A.M. 1969. Long-term survival in a male with 18-trisomy syndrome and Wilm's tumor. Pediatrics 44: 111-116.

Ozawa, H., Tanaka, Y., and Tamura, S. 1974. A case of retinoblastoma with 13q-deletion syndrome in Japanese. Presented at the 28th Actor Societities Ophthalmologicae Japonicae.

Stoll, C., Messer, J., and Vors, J. 1974. Translocation t(2;14) é quilibrée chez une mére et trisomie partielledúne partie du bras court dún chromosome No. 2 chez deux de ses enfants. Ann. Genet. 17: 193-196.

Wilsom, M.G., Melnyk, J., and Towner J.W. 1969. Retinoblastoma and deletion D(14) syndrome. J. Med. Genet. 6: 322-327.

Yamazaki, Y. 1978. A case of neuroblastoma with 3q trisomy in Japanese. Presented at the 13th Japanese society of Pediatric Surgeons in Kanto Kōshinetsu District. 